\title{
Neuronal correlates of fear conditioning in the bed nucleus of the stria terminalis
}

\author{
Darrell Haufler, ${ }^{1,2}$ Frank Z. Nagy, ${ }^{1,2}$ and Denis Pare ${ }^{1,3}$ \\ ${ }^{1}$ Center for Molecular \& Behavioral Neuroscience, Rutgers State University, Newark, New Jersey 07102, USA
}

\begin{abstract}
Lesion and inactivation studies indicate that the central amygdala $(\mathrm{CeA})$ participates in the expression of cued and contextual fear, whereas the bed nucleus of the stria terminalis (BNST) is only involved in the latter. The basis for this functional dissociation is unclear because CeA and BNST form similar connections with the amygdala and brainstem fear effectors. To address this question, we recorded neurons in the anterolateral $(A L)$ and anteromedial (AM) regions of BNST in rats subjected to auditory fear conditioning. During habituation, few neurons were responsive to the conditioned stimulus (CS). After fear conditioning, $20 \%$ of BNST-AL neurons developed inhibitory responses to the CS. In BNST-AM, $26 \%$ of neurons developed positive CS responses. The behavior of BNST-AM and -AL neurons during contextual fear paralleled their CS responsiveness: More BNST-AM neurons fired at higher rates during contextual freezing than movement, whereas the opposite was seen in BNST-AL cells. These findings point to regional differences in the activity of BNST-AL and -AM in relation to learned fear, raising the possibility that they exert opposite influences on fear output networks. However, given the similar behavior of BNST-AM and -AL neurons in relation to cued and contextual fear, it remains unclear why lesion and inactivation of BNST differentially affect these two types of fear. Either neurons in a different BNST sector, not explored here, show a different activity profile in relation to the two forms of fear or inactivation/ lesion studies inadvertently affected a structure adjacent to BNST, which is involved in contextual fear.
\end{abstract}

The bed nucleus of the stria terminalis (BNST) and the central amygdala (CeA) are major components of an anatomical entity named the extended amygdala (Alheid and Heimer 1988; de Olmos and Heimer 1999). This notion stems from similarities in the morphology and transmitter content of BNST and CeA neurons (for review, see McDonald 2003), shared inputs from the basolateral amygdala (BSA) (Krettek and Price 1978a,b; Paré et al. 1995; Savander et al. 1995; Dong et al. 2001a) as well as common projections to brainstem nuclei that generate various aspects of fear/anxiety responses (Hopkins and Holstege 1978; Sofroniew 1983; Veening et al. 1984; Holstege et al. 1985; Dong et al. 2000, 2001b; Dong and Swanson 2003, 2004, 2006a,b,c).

Despite these anatomical similarities, however, BNST and CeA appear to play different roles. For instance, local drug infusion (Kim et al. 1993; Wilensky et al. 2006), lesion (Hitchcock and Davis 1987, 1991; LeDoux et al. 1988; Campeau and Davis 1995; Jimenez and Maren 2009), optogenetic (Ciocchi et al. 2010), and unit recording (Duvarci et al. 2011) studies suggest that CeA is required for the rapid expression of conditioned fear responses to discrete sensory cues (however, see Koo et al. 2004; Pitts et al. 2009), functions that are left intact by BNST lesions (Walker and Davis 1997; Gewirtz et al. 1998; Sullivan et al. 2004). Instead, BNST lesions interfere with the development of longer "anxiety-like" states in response to more diffuse environmental contingencies, responses that often persist after the threat has vanished (for reviews, see Sullivan et al. 2004; Duvarci et al. 2009; Walker et al. 2009). In particular, BNST lesions were reported to disrupt corticosterone and freezing responses to contextual stimuli that were previously associated with aversive outcomes (Sullivan et al. 2004). Importantly, dissociation between CeA and BNST functions is not only seen in

\footnotetext{
${ }^{2}$ These authors contributed equally to this work.

${ }^{3}$ Corresponding author

E-mail pare@andromeda.rutgers.edu

Article is online at http://www.learnmem.org/cgi/doi/10.1101/Im.031799.113.
}

aversive learning paradigms but also in response to some unconditioned stimuli (Fendt et al. 2003).

Given their common inputs from the basolateral amygdala and overlapping projections to fear effector neurons, the basis for the functional dissociation between BNST and CeA is unclear. To shed light on this question, we recorded anterior BNST neurons in freely moving rats subjected to an auditory fear conditioning paradigm.

\section{Results}

Nomenclature used to designate different BNST subregions

As shown in Figure 1, all our recordings were obtained dorsal to the anterior commissure, in the anterior third of BNST. Previously, this BNST region was divided in multiple subnuclei based on cytoarchitectural and immunohistochemical criteria (Ju and Swanson 1989; Ju et al. 1989). However, due to the difficulty of unambiguously identifying these subnuclei in sections stained with cresyl violet, we simply divided our recording sites in two groups, based on their position relative to the intra-BNST component of the stria terminalis. Indeed, this fiber bundle separates the anterior BNST in two large sectors: medial (BNST-AM) and lateral (BNST-AL). The correspondence between these two regions and the subnuclei identified by Swanson and colleagues (Ju and Swanson 1989; Ju et al. 1989) is as follows: BNST-AL corresponds to Swanson's oval, juxtacapsular, and anterolateral subnuclei.

2013 Haufler et al. This article is distributed exclusively by Cold Spring Harbor Laboratory Press for the first 12 months after the fullissue publication date (see http://learnmem.cshlp.org/site/misc/terms. xhtml). After 12 months, it is available under a Creative Commons License (Attribution-NonCommercial 3.0 Unported), as described at http://creativecommons.org/licenses/by-nc/3.0/. 
A
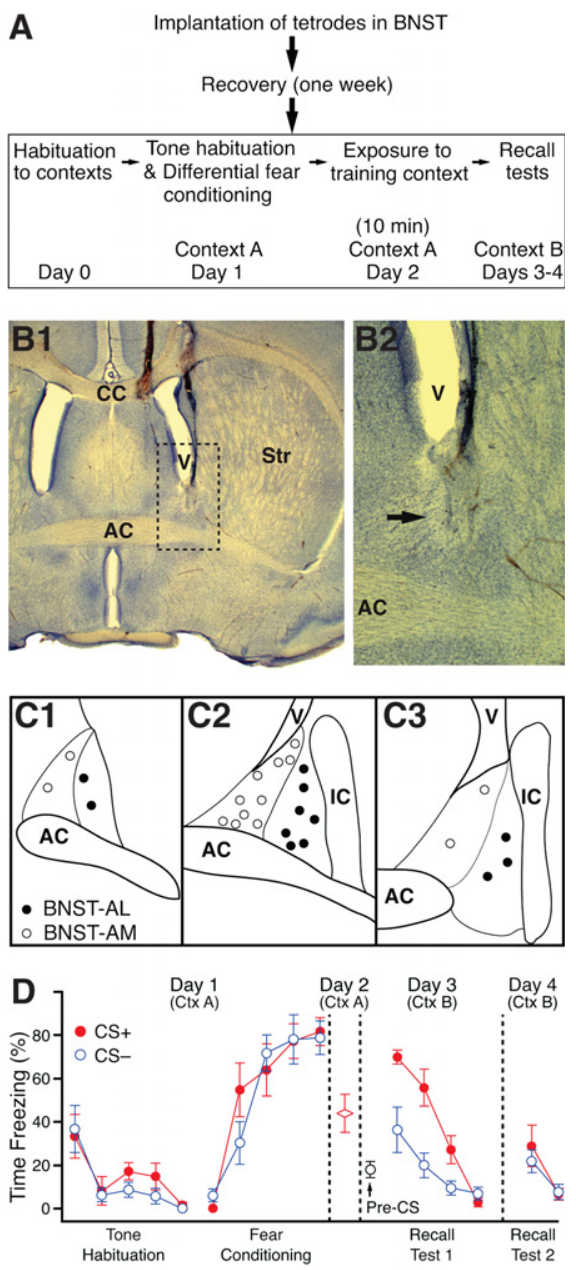

Figure 1. Experimental paradigm, location of recording sites, and behavioral results. (A) Experimental paradigm. After implantation of tetrodes in BNST and recovery from surgery, rats were subjected to a differential auditory fear conditioning paradigm. On Day 0 , rats were habituated to the training contexts $A$ and $B$. On Day 1 , in context $A$, they were first habituated to the $\mathrm{CS}^{+}$and $\mathrm{CS}^{-}$and then subjected to fear conditioning session where the two CSs were presented an equal number of times in random order with only the $\mathrm{CS}^{+}$co-terminating with a footshock. On Day 2, they were exposed to the training context A with no tone presentations to assess contextual fear. On Days 3 and 4 , two recall tests were conducted in context 5. (B) Histological verification of recording site. (B1) Photomicrograph showing a coronal section at the level of BNST-AL. The area enclosed in the dashed rectangle is expanded in B2. Arrow points to small electrolytic lesion performed at the conclusion of the experiment to mark a recording site. (AC) Anterior commissure, (CC) corpus callosum, (Str) striatum, (V) ventricle. (C) Location of wellpositioned tetrodes. Three antero-posterior levels arranged from the most rostral (C1) to the most caudal (C3). Filled and empty circles represent tetrode placements in BNST-AL and -AM, respectively. $(D)$ Percent time (average \pm SEM) the rats $(n=8)$ spent freezing during the $\mathrm{CS}^{+}$ (red circles), $\mathrm{CS}^{-}$(blue circles) or during exposure to the training context (red diamond) in various phases of the behavioral protocol ( $x$-axis). For Day 1 , we plot freezing to individual CSs. For Days 3 and 4 , blocks of five CSs were used to compute the averages. Empty black circle indicates pre-CS freezing during recall test 1 . Note that $5 \mathrm{~min}$ elapsed between placement of the rats in context $B$ and presentation of the first CS. Pre-CS freezing was measured for the last $4 \mathrm{~min}$ of this period.

BNST-AM corresponds to Swanson's anterodorsal subnucleus. Note that in more recent publications (Dong and Swanson 2006a), Swanson also terms the latter region BNST-AM.

\section{Database}

Histological verification of recording sites (Fig. 1B,C) revealed that tetrodes reached their intended targets (BNST-AL and/or -AM) in seven of the eight rats. Units recorded with misplaced tetrodes were excluded from the analyses. Overall, samples of 47-56 BNST-AL and 65-105 BNST-AM units were recorded on each day of the conditioning protocol. The locations of well-positioned tetrodes are shown in Figure 1C. Electrodes were not moved during the behavioral protocol unless units were lost overnight across all tetrodes within a bundle. In such rare cases, the tetrode bundle was lowered $60 \mu \mathrm{m}$. Although the electrodes were generally not moved, spike shapes varied from day to day in a proportion of units. Therefore, below it is assumed that different cells were recorded on each day.

\section{Impact of differential fear conditioning}

After electrode implantation and recovery from surgery, rats were trained on cued (auditory) fear conditioning while recording BNST activity. As summarized in Figure 1A, the behavioral protocol included habituation to the training contexts (Fig. 1A, Day 0) followed the next day by habituation to the auditory $\mathrm{CS}^{+}$and $\mathrm{CS}^{-}$, and then differential fear conditioning in context A (Day 1) (Fig. 1A). Twenty-four hours later, contextual fear memory was assessed in context A for 10 min (no CS, Day 2) (Fig. 1A). Finally, two recall tests of cued fear memory were performed on consecutive days in context B (Days 3 and 4) (Fig. 1A).

Figure 1D illustrates the percent time rats spent freezing during the various phases of the behavioral protocol. Red and blue circles represent freezing to the $\mathrm{CS}^{+}$and $\mathrm{CS}^{-}$, respectively. The red diamond represents contextual freezing in context A. Relative to the last $\mathrm{CS}^{+}$and $\mathrm{CS}^{-}$of habituation, fear conditioning caused a significant increase in freezing levels to the $\mathrm{CS}^{+}\left(\mathrm{CS}^{+} 5,81.9 \% \pm\right.$ $6.5 \%)$ and $\mathrm{CS}^{-}\left(\mathrm{CS}^{-} 5,78.9 \% \pm 7.8 \%\right.$, paired $t$-tests, $\left.P<0.001\right)$. The next day, in the absence of auditory stimuli, the rats exhibited robust freezing to the training context (A, $43.9 \% \pm 8.8 \%$, red diamond). On Day 3, rats showed little freezing prior to presentation of the auditory stimuli (pre-CS freezing, $17.9 \% \pm 3.8 \%$, black circle) in context $\mathrm{B}$. However, the first few $\mathrm{CS}^{+}$elicited large increases in freezing $\left(\mathrm{CS}^{+} 1-5,69.9 \% \pm 3.2 \%\right)$ that gradually diminished with additional $\mathrm{CS}^{+}$presentations $\left(\mathrm{CS}^{+} 16-20: 2.8 \% \pm 2.2 \%\right.$, paired $t$-test, $P<0.001$ ). Although discrimination between to $\mathrm{CS}^{+}$and $\mathrm{CS}^{-}$was imperfect, freezing to the $\mathrm{CS}^{-}\left(\mathrm{CS}^{-} 1-5\right.$, $36.3 \% \pm 10.5 \%$ ) was significantly lower than to the $\mathrm{CS}^{+}$(paired $t$-test, $P=0.002$ ). On Day 4 , the first few $\mathrm{CS}^{+}$presentations again elicited freezing $\left(\mathrm{CS}^{+} 1-5,28.8 \% \pm 9.5 \%\right)$ that extinguished with additional presentations of the $\mathrm{CS}^{+}\left(\mathrm{CS}^{+} 6-10,6.6 \% \pm 2.7 \%\right)$.

Overall, these results suggest that the differential auditory fear conditioning paradigm used in this study led to the formation of a fear memory to the training context and $\mathrm{CS}^{+}$. Although discrimination between the $\mathrm{CS}^{+}$and $\mathrm{CS}^{-}$was imperfect, fear responses to the $\mathrm{CS}^{+}$were clearly stronger than those to the $\mathrm{CS}^{-}$ during the first recall test.

\section{Cellular correlates of cued fear memory in BNST-AL and -AM}

To analyze training-induced changes in auditory responsiveness, we first computed the firing rate of each unit in 5-sec bins, from $20 \mathrm{sec}$ before to $120 \mathrm{sec}$ after the onset of the $\mathrm{CS}^{+}$and $\mathrm{CS}^{-}$. We obtained separate averages for the habituation phase (trials $3-5$ ), the first two and last three $\mathrm{CS}^{+}$and $\mathrm{CS}^{-}$of training, as well as the first and last five $\mathrm{CS}^{+}$and $\mathrm{CS}^{-}$of the two recall tests. For each average, we then $z$-scored the data to firing rate variations seen in the pre-CS period. Next, to determine whether a CS-evoked change in firing rate was significant, we separately averaged the $z$-scores 
of each cell during the six 5-sec bins of the $\mathrm{CS}^{+}$or $\mathrm{CS}^{-}$and assessed whether it differed from the baseline period by $\pm 1.96 z$ or more (yielding a significance threshold of $P \leq 0.05$ ). The results of these analyses are shown in Figures 2-6, including group analyses and individual examples of significantly responsive cells.

Figure 2 illustrates the proportion of cells responsive to the $\mathrm{CS}^{+}$(Fig. 2A) or $\mathrm{CS}^{-}$(Fig. 2B) in the different phases of the behavioral protocol, combining the results obtained in BNST-AL and -AM. The proportion of responsive cells changed depending on the phase of the behavioral protocol. To determine if these changes were statistically significant, we used a $\chi^{2}$ test. This analysis revealed a significant dependence $(P<0.0001)$ between response type to the $\mathrm{CS}^{+}$(response, no response) and behavioral phase (habituation, $\mathrm{CS}^{+} 1$ and 2 or 3-5 of training, first five or last five $\mathrm{CS}^{+}$ of the two recall tests).

Paralleling our behavioral observations, the proportion of cells responsive to the $\mathrm{CS}^{+}$(Fig. 2A) and $\mathrm{CS}^{-}$(Fig. 2B) was low during habituation, and it increased significantly as a result of fear conditioning ( $\chi^{2}$ test, habituation vs. $\mathrm{CS}^{+} 3-5$ of training, $P=0.003)$. The proportion of responsive cells was significantly higher for the $\mathrm{CS}^{+}$than the $\mathrm{CS}^{-}$at the end of training $\left(\chi^{2}\right.$ test, $P=0.015$ ). Without exception, all cells with significant responses to the $\mathrm{CS}^{-}$were also responsive to the $\mathrm{CS}^{+}$and the two CSs elicited responses of the same polarity (see below). Interestingly, the proportion of $\mathrm{CS}^{+}$-responsive cells increased further from the end of fear conditioning to the first recall test $2 \mathrm{~d}$ later $\left(\chi^{2}\right.$ test, $P=$ $0.03)$ and was significantly higher than that to the $\mathrm{CS}^{-}\left(\chi^{2}\right.$ test, $P=0.001$ ). Additional presentation of the $\mathrm{CS}^{+}$during the two recall tests caused a progressive reduction in the proportion of $\mathrm{CS}^{+}$responsive cells such that by the end of the second recall test it became statistically indistinguishable from that seen during habituation.

In the analyses presented so far, we considered all cells with significant responses, whether these responses consisted of an increase or a decrease in firing rate. We now consider the polarity of their responses. However, because the proportion of cells with significant responses to the $\mathrm{CS}^{-}$was low (Fig. 2B), the following analyses will focus on $\mathrm{CS}^{+}$-evoked activity. As shown in Figure 3, the relative incidence of cells with inhibitory (blue, "Off-cells") vs. excitatory (red, "On-cells") responses to the $\mathrm{CS}^{+}$differed between BNST-AL and -AM. In BNST-AL (Fig. 3A), fear conditioning caused a large increase in the proportion of Off-cells $\left(\mathrm{CS}^{+} 1\right.$ and 2 vs. $3-5$ of training, $\chi^{2}$ test, $P=0.0022$ ) with little change in the incidence of On-cells. Two days later, during the first five $\mathrm{CS}^{+}$of the recall
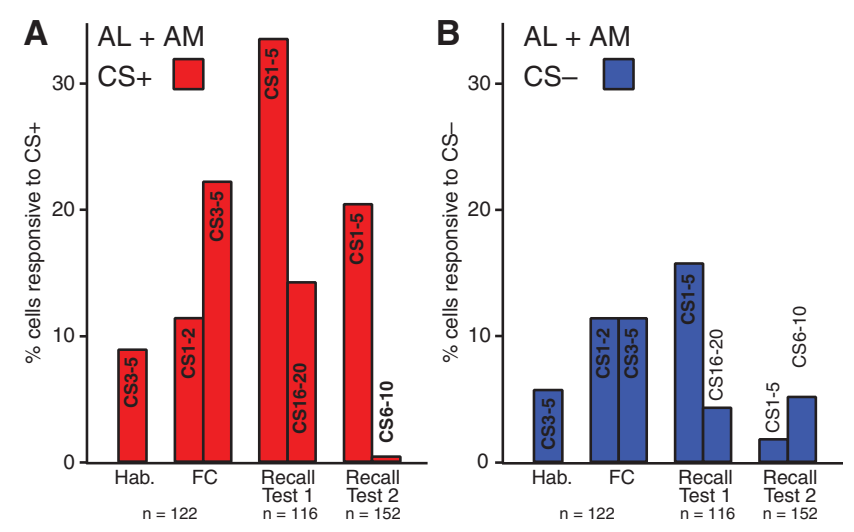

Figure 2. Differential fear conditioning alters the responses of BNST neurons in a CS-specific manner. Proportion of BNST cells (AL and AM combined) with significant responses (increased or decreased) to the $\mathrm{CS}^{+}(A)$ or $\mathrm{CS}^{-}(B)$ during the various phases of the behavioral protocol ( $x$-axis). The number of recorded cells is indicated at the bottom of the graphs.
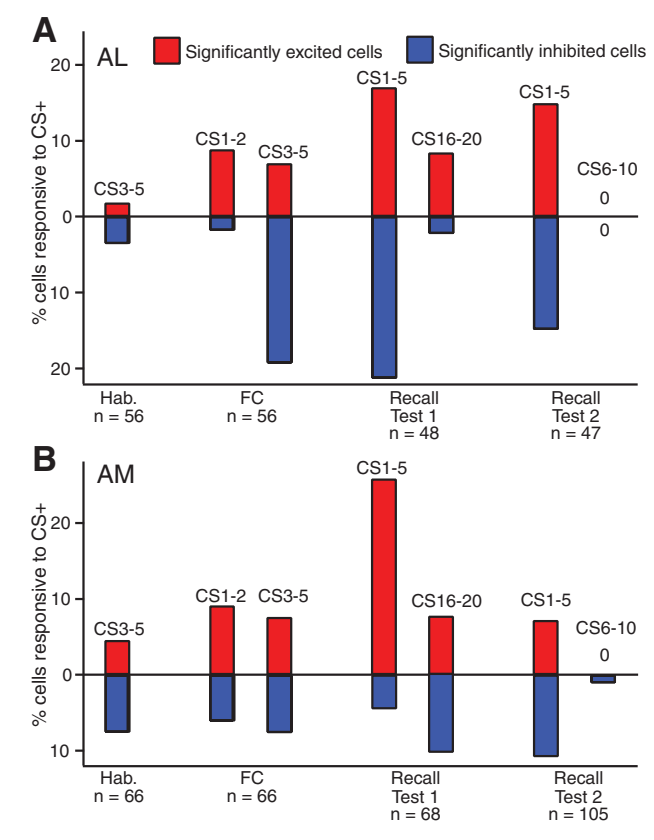

Figure 3. Opposite polarity of changes in CS responsiveness in BNST-AL vs. BNST-AM neurons. Proportion of BNST-AL $(A)$ and BNST-AM $(B)$ cells with significant excitatory (red) or inhibitory (blue) responses to the $\mathrm{CS}^{+}$during the various phases of the behavioral protocol ( $x$-axis). The number of recorded cells is indicated at the bottom of the graphs.

test, the incidence of Off-cells remained similarly high, whereas the proportion of On-cells augmented. However, the latter change did not reach significance. With additional presentations of the $\mathrm{CS}^{+}$, roughly equal but decreasing proportions of cells showed inhibitory and excitatory responses.

Figure $4 \mathrm{~A}$ illustrates a representative example of BNST-AL neuron with inhibitory responses to the $\mathrm{CS}^{+}$during the first recall test. In the top panel, each of the 20 lines shows the activity of the cell from the first (top) to the last (bottom) $\mathrm{CS}^{+}$(gray shading) of recall test 1 . The bottom panel shows the average firing rate of the same cell during the first (red) and last (black) five $\mathrm{CS}^{+}$of the first recall test. The first five $\mathrm{CS}^{+}$elicited a sustained decrease in firing rate, essentially silencing the cell for the entire duration of the $\mathrm{CS}^{+}$. Across all BNST-AL cells with inhibitory responses to the $\mathrm{CS}^{+}$, the firing rate during the first five $\mathrm{CS}^{+}$of recall test 1 decreased to $27.3 \% \pm 10.8 \%$ of baseline. Additional presentations of the $\mathrm{CS}^{+}$ caused a reduction of the $\mathrm{CS}^{+}$-evoked inhibition $\left(\mathrm{CS}^{+} 16-20\right.$, to $48.5 \% \pm 12.1 \%$ of baseline; paired $t$-test, $P=0.00011$ ).

In contrast with the results obtained in BNST-AL, the proportion of BNST-AM units with inhibitory or excitatory responses to the $\mathrm{CS}^{+}$did not change on the training day (compare $\mathrm{CS}^{+} 1$ and 2 vs. $3-5$ of training in Fig. 3B). Two days later, during the first five $\mathrm{CS}^{+}$of the recall test, a large and significant increase in the incidence of On-cells was observed $\left(\mathrm{CS}^{+} 3-5\right.$ of training vs. $\mathrm{CS}^{+} 1-5$ of recall test $1, \chi^{2}$ test, $P=0.0021$ ) with little change in the proportion of Off-cells. Additional presentations of the $\mathrm{CS}^{+}$reduced the incidence of On-cells.

Figure 4B illustrates a representative example of BNST-AM neuron with excitatory responses to the $\mathrm{CS}^{+}$during recall test 1. Typical for these cells, the increase in firing rate elicited by the $\mathrm{CS}^{+}$peaked during the first 5 sec of the CS and then decreased later on. Also typical for these cells, additional presentations of the $\mathrm{CS}^{+}$during the recall test caused a reduction of their responses (from $137.6 \% \pm 6.5 \%$ of baseline to $105.7 \% \pm 4.2 \%$ during the first five and last five $\mathrm{CS}^{+}$, respectively; paired $t$-test, $P=0.00055$ ). 
A

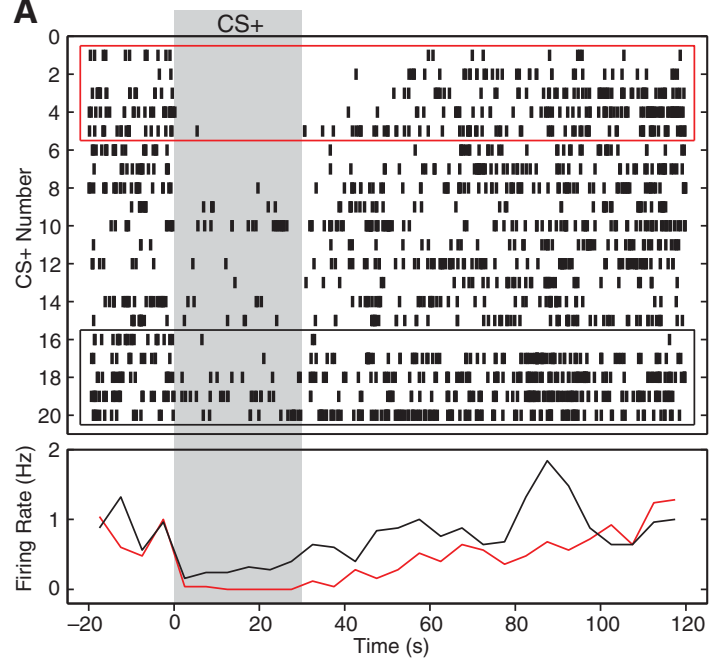

B

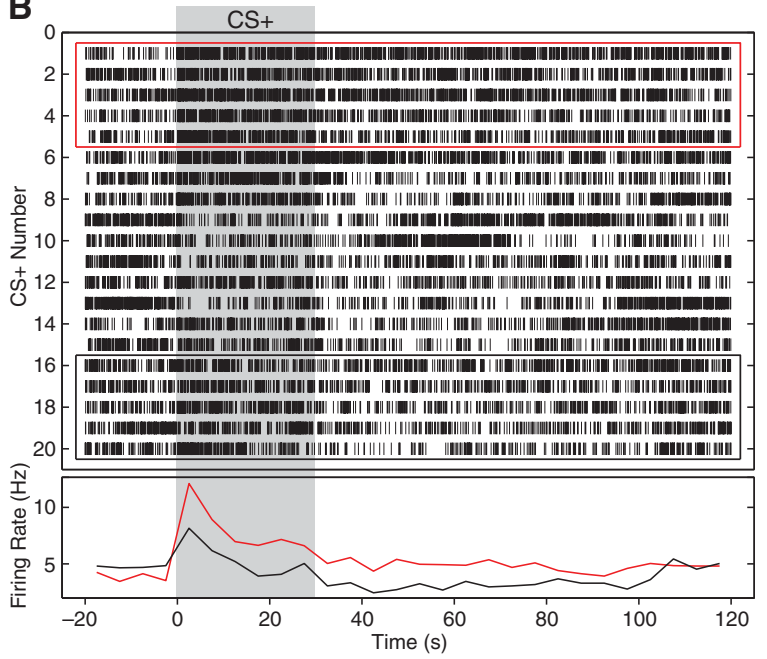

Figure 4. Examples of BNST neurons with inhibitory and excitatory $\mathrm{CS}^{+}$responses at recall. $(A) \mathrm{BNST}$-AL cell with inhibitory response to the $C S^{+}$. (B) BNST-AM neurons with excitatory responses to the $\mathrm{CS}^{+}$. In the top panels of $A$ and $B$, each of the 20 horizontal lines shows the activity of the cell from the first (top) to the last (bottom) $\mathrm{CS}^{+}$(gray shading) of recall test 1. Each vertical tick represents one action potential. The bottom panels show the average firing rate of the same cells during the first (red) and last (black) five $\mathrm{CS}^{+}$.

In the $\chi^{2}$ analyses presented in Figures 2 and 3, we reported on the incidence cells with significant responses to the CSs. A limitation of this approach when comparing two cell groups is that it ignores the magnitude of the changes in responsiveness. To address this potential confound, we next compared the average responses of BNST-AL (Fig. 5) and BNST-AM (Fig. 6) cells from habituation to
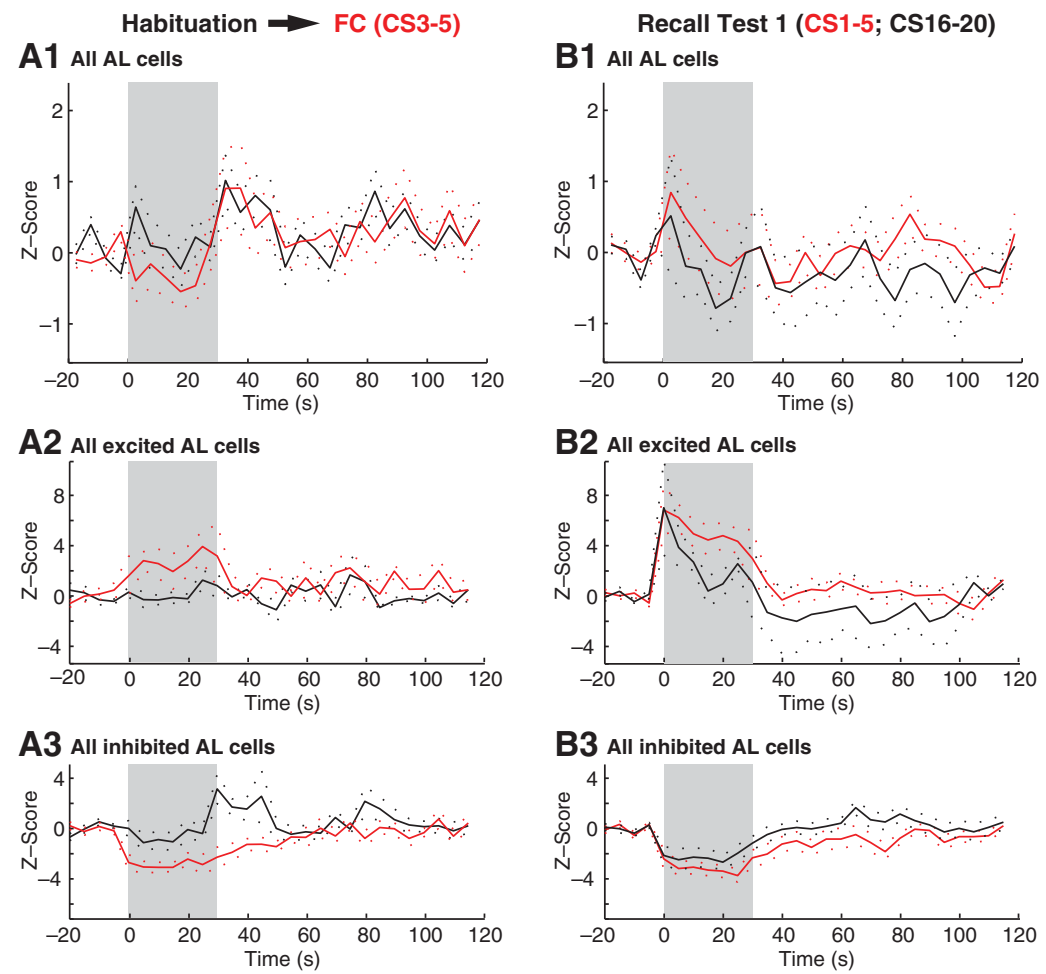

Figure 5. Grand average of the responses of BNST-AL neurons to the $\mathrm{CS}^{+}$(gray shading) $(A)$ during habituation (black) and at the end of training (red) as well as during the recall test ( $B$ ) (red and black, first and last five $\mathrm{CS}^{+}$, respectively). In $A 1$ and $B 1$, all available BNST-AL cells were included in the averages, whereas the averages shown in $A 2, B 2, A 3$ and $B 3$ were restricted to cells with significant excitatory or inhibitory responses, respectively. Dotted lines represent the SEM. the end of training (left) and during the recall test (right). Separate averages are provided (from top to bottom) for all cells combined, On-cells, and Off-cells. Comparing the average behavior of BNST-AL and -AM neurons during the recall test (Figs. 5B and 6B respectively) reveals striking differences that are consistent with the incidence analyses presented in Figure 3. Due to response heterogeneity among BNST-AL neurons (Fig. $5 \mathrm{~B} 2, \mathrm{~B} 3)$, no significant change in CS responsiveness is seen in the grand average of all BNST-AL neurons from the beginning (red) to the end (black) of the first recall test. This contrasts with the grand average of all BNST-AM neurons (Fig. 6B1) where, due to the prevalence of Oncells (Fig. 6B2), a significant increase in activity is apparent at the onset of the recall test (Fig. 6B1, red). Unexpectedly the neuronal responses of BNST-AL cells to the $\mathrm{CS}^{+}$persisted to some extent at the end of the recall test (trials 16-20) (Fig. $5 \mathrm{~B} 2, \mathrm{~B} 3)$, when freezing had fully extinguished (Fig. 1D). This observation might be interpreted as evidence of a persistent associative memory in BNST, which could rekindle fear after extinction.

\section{Comparison of firing rates,} patterns, and spike shapes between $\mathrm{CS}^{+}$-responsive and unresponsive BNST neurons

In contrast with other brain structures such as cortex (Markram et al. 2004) or striatum (Tepper and Bolam 2004), where the distinctive neurochemical, morphological, and electrophysiological properties of projection cells and interneurons are well known, there is no such clarity in the BNST. A majority of BNST cells are GABAergic/peptidergic and a minority 

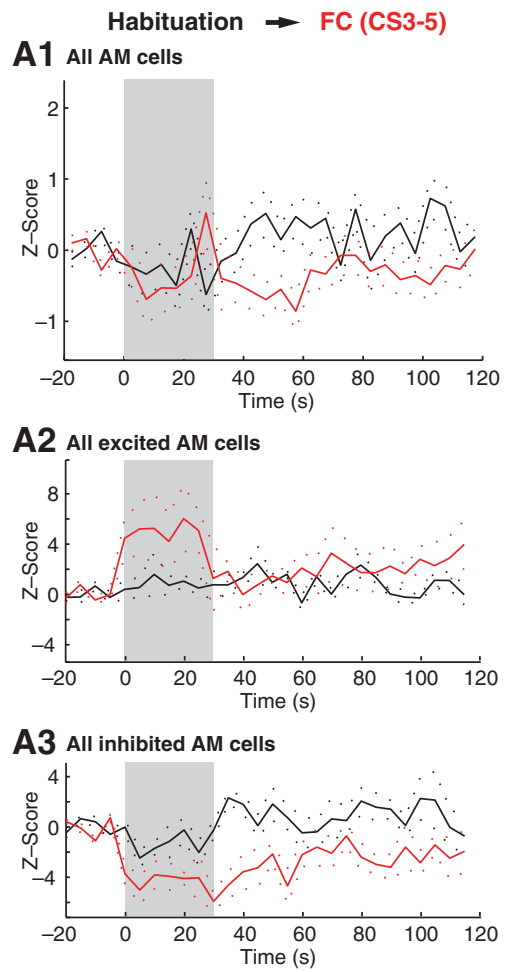
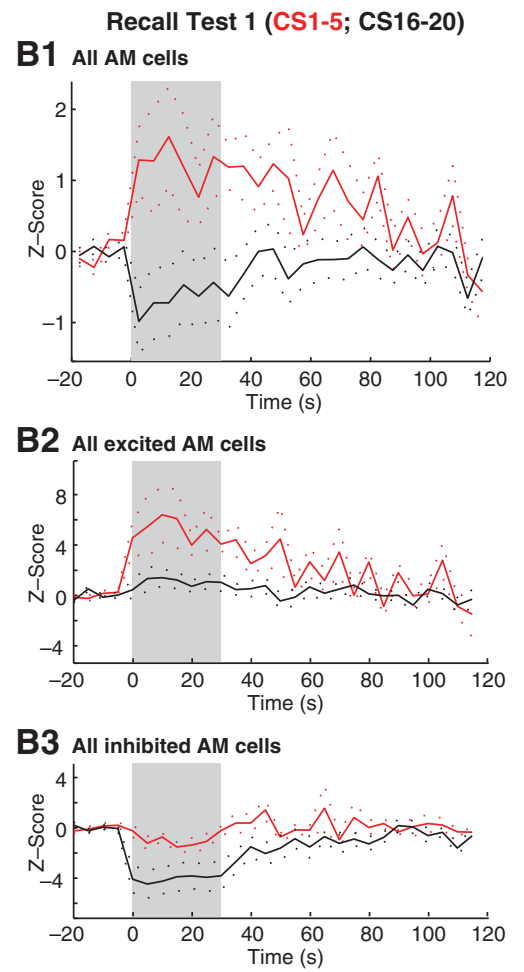

Figure 6. Grand average of the responses of BNST-AM neurons to the $\mathrm{CS}^{+}$(gray shading) $(A)$ during habituation (black) and at the end of training (red) as well as during the recall test $(B)$ (red and black: first and last five $\mathrm{CS}^{+}$, respectively). In $A 1$ and $B 1$, all available BNST-AM cells were included in the averages, whereas the averages shown in $A 2, B 2, A 3$ and $B 3$ were restricted to cells with significant excitatory or inhibitory responses, respectively. Dotted lines represent the SEM.

are glutamatergic (Day et al. 1999; Poulin et al. 2009; Kudo et al. 2012). Given the pattern of results obtained in retrograde tracing studies (Day et al. 1999; Herman et al. 2004; Kudo et al. 2012), it is likely that a large proportion of the GABAergic cells and at least some of the glutamatergic neurons are projection cells. Similarly, although electrophysiological studies have distinguished three main cell types in BNST-AL (Hammack et al. 2007; Hazra et al. 2011; Rodríguez-Sierra et al. 2013), it remains unclear whether all or a subset of each class correspond to projection cells or interneurons. Nevertheless, in an attempt to determine whether distinct cell types respond differently to the $\mathrm{CS}^{+}$, we next compared the properties of neurons with significant vs. nonsignificant responses to the $\mathrm{CS}^{+}$during the recall test $\left(\mathrm{CS}^{+} 1-5\right)$.

Although the spontaneous firing rates of BNST cells ranged widely (from near zero to $32 \mathrm{~Hz}$ ), most BNST-AL and -AM neurons had low firing rates $(\mathrm{AL}, 82 \%<4 \mathrm{~Hz} ; \mathrm{AM}, 84 \%<4 \mathrm{~Hz}$ ), with no overall difference in the firing rate of the cells recorded at these two sites $(2.22 \pm 0.54 \mathrm{~Hz})$ and BNST-AM $(3.14 \pm 0.82 \mathrm{~Hz}$; Wilcoxon Rank-Sum test, $P=0.43)$. To determine whether there was a relationship between the $\mathrm{CS}^{+}$responsiveness of BNST-AL or -AM neurons (excited, inhibited, no response) and their firing properties (baseline firing rate or spike duration), we computed Kruskal-Wallis one-way ANOVAs. For baseline firing rates, both ANOVAs reached significance (AL, $P=0.035$; AM, $P=0.004$ ). Post-hoc Wilcoxon Rank-Sum tests with Bonferroni correction of the significance level revealed that there was a trend for BNST-AM On-cells to have higher baseline firing rates $(5.4 \pm 1.5$ $\mathrm{Hz})$ than Off-cells $(0.6 \pm 0.3 \mathrm{~Hz}, P=0.07)$ or unresponsive neurons $(2.7 \pm 0.8 \mathrm{~Hz}, P=0.05)$. For BNST-AL cells, none of the post-hoc comparisons approached significance. However, it was clear that BNST-AL cells had significantly lower baseline firing rates than
BNST-AM On cells $(P=0.022)$. With spike duration, the ANOVA did not reach significance for BNST-AM cells $(P=0.39)$ but it did for BNST-AL cells $(P=0.023)$. Post-hoc Wilcoxon Rank-Sum tests revealed that there was a trend for BNST-AL Off cells to generate spikes of longer duration $(0.52 \pm 0.08 \mathrm{msec})$ than unresponsive cells $(0.39 \pm 0.03 \mathrm{msec}$, $P=0.08)$. Finally, since earlier patchclamp studies reported that a major physiological class of BNST neurons generate low-threshold spike bursts (Hammack et al. 2007; Hazra et al. 2011; Rodríguez-Sierra et al. 2013), we compared the incidence of bursting and nonbursting neurons among On-cells, Off-cells, and unresponsive neurons of BNST-AL or -AM but found no significant differences $(P \geq 0.3)$.

\section{Cellular correlates of contextual fear memory in BNST-AL and -AM}

Because prior behavioral studies have revealed that BNST lesions reduce contextual fear (Sullivan et al. 2004; Duvarci et al. 2009), we next studied the activity of BNST-AL $(n=38)$ and AM $(n=69)$ neurons during the 10-min exposure to the training context on Day 2, when the rats exhibited high levels of contextual freezing (Fig. 1D, red diamond). We observed that most BNST-AM cells fired at a higher rate during freezing than movement, whereas BNST-AL cells tended to show the opposite pattern of activity. Representative examples of BNST-AM and -AL neurons with respectively higher and lower activity during behavioral freezing than movement are provided in Figure 7, A and B, respectively.

To address this quantitatively, we compared the firing rate of each cell during multiple epochs of freezing vs. movement. The spike trains were first smoothed with a Gaussian kernel with a standard deviation of $0.25 \mathrm{sec}$. The resulting rate estimate was then sampled at 0.5 -sec intervals and periods of freezing and movement were compared using an unpaired $t$-test, in each cell independently (Fig. 8A). As shown in Figure 8B, a similar proportion of BNST-AM (47.8\% or 33 of 69 ) and BNST-AL cells (36.8\% or 14 of 38) fired at significantly different rates in epochs of high vs. low fear. However, paralleling the pattern of results seen with responses to the $\mathrm{CS}^{+}$, the majority of significant BNST-AM cells ( $66.6 \%$ or 22 of 33 ) fired at higher rates during freezing than movement, whereas most significant BNST-AL cells did the opposite (71.4\% or 10 of 14 ; Fisher exact, $P=0.015)$. Yet, there were no significant differences in the baseline firing rates (measured during wakefulness in the home cage) of neurons with higher vs. lower firing rates during freezing among or between BNST-AL or -AM neurons (Wilcoxon Rank-Sum tests, $P \geq 0.12$ ).

Although prior lesion studies suggest that BNST plays an important role in the genesis of contextual freezing, it remains possible that the differences in firing rates described above do not relate to the affective state of the rats but to another factor such as proprioceptive feedback. To address this possibility, we compared the spontaneous firing rates of BNST-AL and -AM neurons while the animals were in a neutral transfer cage prior to placement in context A (10-min epochs). In this environment, rats 


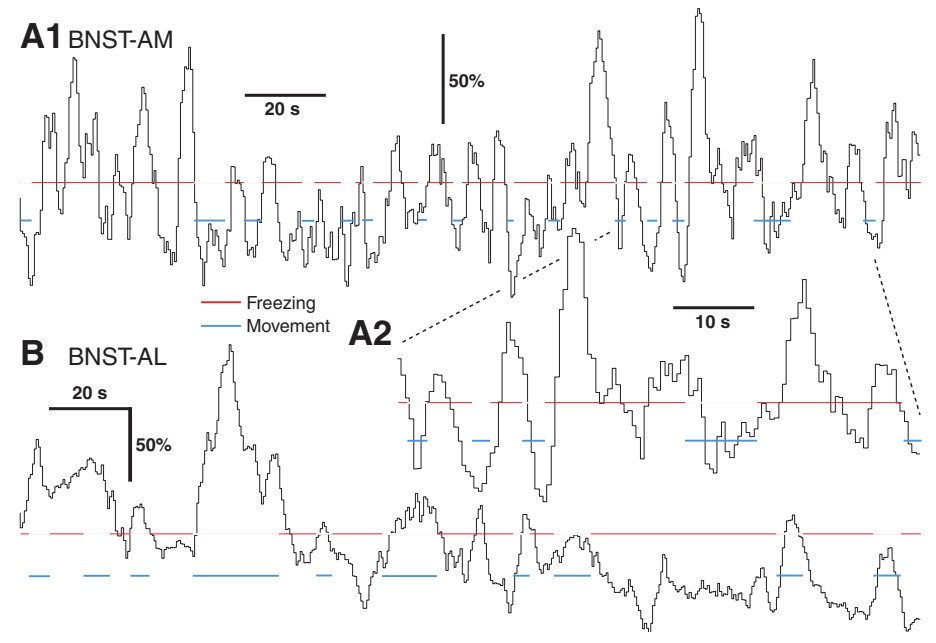

Figure 7. Differential activity of BNST-AM and -AL neurons during movement vs. contextual freezing. Black traces depict normalized fluctuations in firing rate during periods of freezing (red lines) and movement (blue lines). (A) Fluctuations in the firing rate of five simultaneously recorded BNST-AM cells, expressed as percent of average. A portion of $A 1$ (dashed lines) is shown with an expanded time base in $A 2$. (B) Fluctuations in the firing rate of three simultaneously recorded BNST-AL cells, expressed as percent of average. In $A$ and $B$, prior to averaging, the firing rates of individual cells was normalized to the average of the entire period so as to give an equal weight to the data obtained in each cell. Note that to optimize the temporal resolution of the behavioral measurements, the exact onset and offset times of visually identified periods of freezing and movement were determined using frame-by-frame analysis of the video recordings. Data depicted in $A$ and $B$ were obtained in different rats.

were generally active. Periods of immobility were almost always followed by a shift in their behavioral state to slow-wave sleep (SWS). This shift was easy to identify because it coincided with a dramatic increase in the power of large amplitude slow oscillations $\leq 4 \mathrm{~Hz}$ in the local field potentials.

Thus, using the same approach as in the above, we compared firing rates during movement vs. immobility, but excluding periods of overt SWS. Respectively, 33.3\% and 39.3\% of BNST-AL and -AM neurons were found to have significantly different firing rates in the two conditions. However, the proportion of cells with higher firing rates in one condition or the other did not differ significantly (Fisher exact: $\mathrm{AM}, P=0.23 ; \mathrm{AL}, P=0.43$ ).

\section{Discussion}

We have studied the behavior of anterior BNST neurons during cued and contextual fear. The interest of this question stems from earlier work indicating that BNST and CeA, despite forming similar connections with the basolateral amygdala (BLA) and brainstem fear effectors, are differentially involved in contextual vs. cued fear. Surprisingly, while we observed regional differences in BNST activity in relation to fear, the pattern of results was similar for contextual and cued fear. The significance of these findings is considered below.

\section{Prior lesion and inactivation studies on the role of BNST in contextual and cued fear}

There is consensus that BNST is involved in the genesis of contextual, but not cued fear. Reversible inactivation (Walker and Davis 1997) as well as electrolytic (Gewirtz et al. 1998; Sullivan et al. 2004; Waddell et al. 2006) or neurotoxic (LeDoux et al. 1988; Duvarci et al. 2009) lesions of BNST impair the expression of contextual but not cued fear, unless the CS is very long (Waddell et al. 2006) or the temporal relationship between the CS and US is ambiguous (Walker et al. 2009). However, more recent reports using techniques that allow selective manipulations of different
BNST regions (Kim et al. 2013) or of different cell types within these regions (Jennings et al. 2013) revealed that BNST is functionally heterogeneous. Consistent with this notion, some early studies suggested that BNST activity, while not required for generating learned fear to cues, exerts a tonic inhibitory influence on fear output networks. Indeed, intra-BNST infusions of muscimol was found to enhance fear-potentiated startle (Meloni et al. 2006). Also, presentation of a fear-eliciting CS together with a conditioned inhibitor was found to increase Fos expression in BNST relative to that in animals only presented with the CS (Campeau et al. 1997). Last, intra-BNST infusions of calcitonin gene-related peptide (CGRP) was reported to enhance startle and increase Fos expression in CeA (Sink et al. 2011). However, a patch-clamp study found that CGRP potentiates GABAergic inhibition in neurons of BNST-AL (Gungor and Pare 2012), the BNST region receiving CGRP inputs from the parabrachial nucleus (Gustafson and Greengard 1990; Dobolyi et al. 2005). Since most BNST neurons are GABAergic (Esclapez et al. 1993; Poulin et al. 2009), these results suggest the startle enhancement produced by intra-BNST infusions of CGRP is due to the inhibition of BNST-AL neurons and consequent disinhibition of CeA.

\section{Activity of BNST neurons in relation to cued and contextual fear}

Overall, the findings reviewed above support the view that BNST exerts a dual influence over fear expression. On the one hand, BNST supports contextual fear; on the other, there is evidence that BNST, most likely its anterolateral region, exerts an inhibitory influence over fear output networks. As described below, we propose that this apparent contradiction reflects regional
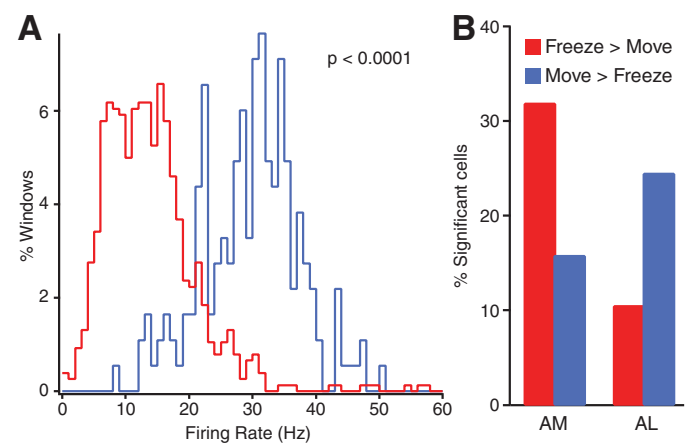

Figure 8. Analysis of fluctuations in firing rates during movement vs. freezing. $(A)$ Frequency distributions of firing rates during freezing (red) or movement (blue) for a BNST-AL cell. The spike train of the cell was first smoothed with a Gaussian kernel with a standard deviation of 0.25 sec. The resulting rate estimate was then sampled at $0.5-\mathrm{sec}$ intervals and frequency distributions of firing rates were computed. $(B)$ Incidence of BNST-AM (left) and AL (right) cells with significantly higher firing rates during freezing (red) or movement (blue). 
heterogeneity in the anterior BNST. Indeed, the present study revealed that BNST-AL and -AM neurons display a different activity profile in relation to learned fear. First, during cued fear conditioning, BNST-AL neurons acquired inhibitory responses to the CS (Off-cells). Two days later, during the recall test, the proportion of Off-cells remained high but an additional subset of cells developed positive responses to the CS (On-cells). In contrast, the CS responsiveness of BNST-AM neurons did not change during training. However, during the recall test $2 \mathrm{~d}$ later, we observed a large increase in the incidence of cells with excitatory responses to the CS. Importantly, BNST-AL and -AM neurons also displayed an opposite activity profile in relation to contextual fear. Indeed, when rats were exposed to the training context the day after fear conditioning, a third of BNST-AM neurons fired at significantly higher rates during freezing than movement. Few BNST-AM cells showed the opposite behavior. By contrast, in BNST-AL, neurons with lower firing rates during freezing prevailed, consistent with the pattern of CS responsiveness described above.

These findings point to regional differences in the activity of BNST-AL and -AM in relation to learned fear, raising the possibility that they exert opposite influences on fear output networks. Several factors likely underlie these differences, including regionally heterogeneous amygdala projections to BNST as well as the intrinsic BNST network. Indeed, the amygdala sends strong but neurochemically diverse projections to BNST: GABAergic/peptidergic inputs from CeA and glutamatergic inputs from BLA (Krettek and Price 1978b; Dong et al. 2001a; McDonald 2003). Importantly, CeA contributes stronger projections to BNST-AL than AM (Dong et al. 2001a). Conversely, a major component of BNST-AL, the oval nucleus, is largely devoid of BLA inputs (Dong et al. 2001a). In addition, a recent in vitro study on the intrinsic connections of BNST reported that BNST-AL neurons receive inhibitory inputs from other BNST neurons (Turesson et al. 2013). Thus, CS-related BLA inputs might excite BNST cells that send GABAergic projections to neurons of the oval nucleus, causing a feedforward inhibition. This inhibition of BNST-AL neurons might be reinforced by CeA inputs, which are much stronger to BNST-AL than -AM (Dong et al. 2001a).

Consistent with the above, there is a correspondence between the CS responsiveness of neurons in the lateral $(\mathrm{CeL})$ and medial (CeM) sectors of CeA and BNST. In particular, most CS-responsive CeM neurons exhibit positive responses to the CS (Ciocchi et al. 2010; Duvarci et al. 2011), as in BNST-AM. In contrast, as in BNST-AL, CeL responses to the CS are heterogeneous, with different CeL neurons exhibiting inhibitory or excitatory responses (Ciocchi et al. 2010; Duvarci et al. 2011). Perhaps not coincidentally, the incidence of CeL Off-cells does not increase during training, but after a consolidation period (Duvarci et al. 2011). In parallel, an inflation of CS-evoked responses develops in BLA (Amano et al. 2011). At present, the cellular interactions leading to these time-dependent changes in CS responsiveness remain unclear. However, given the strong interconnections existing between BLA, CeA, and BNST neurons, a causal relation is likely. Also, considering the dramatic impact of medial prefrontal lesions on the expression of learned fear (Sierra-Mercado et al. 2011) and the preferential innervation of BNST-AM by prelimbic afferents (for review, see McDonald et al. 1999), it is probable that prefrontal inputs also play a role.

\section{Preferential BNST contribution to contextual fear}

The impetus for the present study was to determine why BNST lesion and inactivation interfere with contextual but not cued fear given that BNST and CeA contribute similar projections to brainstem fear effector neurons. Yet, we found that BNST-AM and -AL neurons show a similar differential activity profile in relation to cued and contextual fear. These findings raise the following possibilities. First, it is conceivable that neurons in a different BNST sector, not explored in the present study, show a different activity profile in relation to the two forms of fear. Second, it is possible that earlier inactivation or lesion studies inadvertently affected a structure adjacent to BNST, which is involved in contextual fear. Consistent with this possibility, recent findings implicate components of the septal region in the regulation of fear and anxiety (Yamaguchi et al. 2013). Additional experiments will be required to settle this question.

\section{Materials and Methods}

Procedures were approved by the Institutional Animal Care and Use Committee of Rutgers University, in compliance with the Guide for the Care and Use of Laboratory Animals (DHHS). Our subjects were male Lewis rats (310-360 g, Charles River Laboratories, Wilmington, MA) maintained on a 12 -h lightdark cycle. They were housed individually with ad libitum access to food and water. Prior to the experiments, they were habituated to the animal facility and handling for $1 \mathrm{wk}$.

\section{Surgery}

Eight rats were anesthetized with a mixture of isoflurane and $\mathrm{O}_{2}$, and administered atropine sulfate $(0.05 \mathrm{mg} / \mathrm{kg}, \mathrm{i} . \mathrm{m}$.) to aid breathing. In aseptic conditions, rats were mounted in a stereotaxic apparatus with nonpuncture ear bars. A local anesthetic (bupivacaine, s.c.) was injected in the region to be incised. Fifteen minutes later, the scalp was incised and a craniotomy was performed above BNST. Then, movable bundles of four tetrodes (nichrome microwires, $20-\mu \mathrm{m}$ inner diameter, impedance $100-300 \mathrm{k} \Omega$ following gold plating) were stereotaxically aimed to the lateral and medial parts of the anterior portion of BNST (BNST-AL and BNST-AM, respectively). Tetrode tip positions within a bundle were staggered to facilitate histological reconstructions. The rats were allowed $1 \mathrm{wk}$ to recover from the surgery and then acclimated to handling for two additional days.

\section{Behavioral protocol}

The rats were subjected to a differential fear conditioning paradigm (Fig. 1A). Fear conditioning and recall testing occurred in different contexts (context A and B). For fear conditioning (context A), rats were placed in a rodent conditioning chamber with a metal grid floor (Coulbourn Instruments) that was enclosed within a sound-attenuating chamber, dimly illuminated by a single house light. For testing recall, the chamber contained a black plexiglass floor washed with peppermint soap (context B).

On Day 0, rats were habituated to context A and B for 20 min each. Before and after each context exposure, the animals were placed in their home cage. On Day 1, we performed a tone habituation session (five presentations of the $\mathrm{CS}^{+}$and the $\mathrm{CS}^{-}$, each 30 sec in duration, white noise or $2 \mathrm{kHz}, 80 \mathrm{~dB}$ ). The identity of the $\mathrm{CS}^{+}$and $\mathrm{CS}^{-}$was varied across animals and they were presented in a random order. The $\mathrm{CS}^{-}$served as a nonassociative control. Following habituation, the rats received presentations of five $\mathrm{CS}^{+}$and five $\mathrm{CS}^{-}$, with the $\mathrm{CS}^{+}$co-terminating with a footshock (US, $0.5 \mathrm{~mA}, 1 \mathrm{sec}$ ). On Day 2, to test for contextual fear memory, rats were placed in context $\mathrm{A}$ for $10 \mathrm{~min}$ with no presentations of the $\mathrm{CS}^{+}$or $\mathrm{CS}^{-}$. On Day 3 , in context $\mathrm{B}$, recall of cued fear was tested with 20 additional presentations of the $\mathrm{CS}^{-}$and $\mathrm{CS}^{+}$. Another recall test was performed on Day 4 (10 additional presentations of the $\mathrm{CS}^{+}$and $\mathrm{CS}^{-}$). In all phases, 5 min elapsed between placement of the rats in context A or B and presentation of the first CS. The duration of the CS was always $30 \mathrm{sec}$ and the inter-CS intervals varied between 3 and $4 \mathrm{~min}$. This long interval was selected so that during the recall tests, freezing elicited by one CS would have subsided by the time the next CS is presented. However, note that during fear conditioning, once the first US was administered, rats froze at various times, including during the CSs and 
inter-CS intervals. Much of this freezing likely represents a nonassociative response to the recent US exposure. Behavior was recorded by a video-camera and scored off-line. Time spent freezing (immobility, with the exception of breathing) was measured by an experienced observer with a stopwatch. Contextual freezing was also measured using a custom Matlab script that compared absolute differences in luminosity values between corresponding pixels in successive video frames. Prior to carrying out this analysis, the frames were filtered with a two-dimensional median base filter to remove the so-called "salt-and-pepper" noise in luminosity values of nearby pixels. To detect freezing, we used a uniform threshold of luminosity variations (10\% of maximal seen during locomotor activity) that had to be observed in at least 30 consecutive frames (or $1 \mathrm{sec}$ ). This automated approach closely matched the results obtained with visual scoring $(r=0.9)$.

\section{Unit recording, clustering, and analysis}

BNST unit recordings were performed during all the phases of the behavioral protocol described above. The signals were sampled at $40 \mathrm{kHz}$ and stored on a hard drive. The data were first high-passed filtered using a median-based filter, then thresholded to extract spikes. We then ran PCA on the spikes and the first three components were clustered using KlustaKwik (http://klustakwik. sourceforge.net/). Spike clusters were then refined manually using Klusters (Hazan et al. 2006). The reliability of cluster separation was verified by inspecting auto- and cross-correlograms. Units with unstable spike shapes during a given recording session were excluded from the analyses.

To determine whether cells generated spike bursts akin to those generated by the Type-II BNST-AL and -AM neurons reported in previous in vitro patch-clamp studies (Hammack et al. 2007; Hazra et al. 2011; Rodríguez-Sierra et al. 2013), we fit the tail of the inter-spike interval (ISI) distribution (interval $>100 \mathrm{msec}$ ) to an exponential distribution, the form expected for a random (nonbursting) process. If the observed rate of ISIs $<20 \mathrm{msec}$ spike interval was significantly greater than expected from the exponential approximation extrapolated from high to small interval values, the cell was classified as a bursting neuron.

To determine spike duration, we first selected the tetrode channel where, for a given cell, action potentials had the largest peak-to-trough amplitude. We then measured the spike's halfamplitude duration as the time required for the action potential to rise from, and return to, half of its maximum amplitude (see Barthó et al. 2004).

\section{Statistical analyses}

To assess whether CS-evoked responses were significant, we first computed the firing rate of each unit in 5 -sec bins, from 20 sec before to $120 \mathrm{sec}$ after the onset of the $\mathrm{CS}^{+}$and $\mathrm{CS}^{-}$. Separate averages were obtained for the habituation phase, the first two and last three $\mathrm{CS}^{+}$and $\mathrm{CS}^{-}$of training, as well as the first and last five $\mathrm{CS}^{+}$and $\mathrm{CS}^{-}$of the two recall tests. The data of each average were then $z$-scored to firing rate variations seen in the pre-CS period. A CS-evoked change in firing rate was deemed significant, when the six 5-sec bins of the $\mathrm{CS}^{+}$or $\mathrm{CS}^{-}$differed from the baseline period by $\pm 1.96 \mathrm{z}$ or more. This corresponds to a significance threshold of $P \leq 0.05$. To assess whether the proportion of responsive cells changed significantly depending on the phase of the behavioral protocol, we used a $\chi^{2}$ test that analyzed whether there was a dependence between response type (response, no response) and behavioral phase (habituation, $\mathrm{CS}^{+} 1$ and 2 or 3-5 of training, first five or last five $\mathrm{CS}^{+}$of the two recall tests). It should be noted that there were no significant differences in the effectiveness of the white noise vs. $2-\mathrm{kHz}$ tone in eliciting significant responses from BNST-AL and -AM cells during habituation. Indeed, a $\chi^{2}$ test revealed no significant dependence between response type (increased firing, decreased firing, no response) and the type of auditory stimulus (white noise or $2-\mathrm{kHz}$ tone) $\left(\chi^{2}=1.03, P=0.59\right)$. In addition, the magnitude of significant excitatory or inhibitory responses elicited by the two auditory stimuli did not differ (paired $t$-tests, $P=0.4256$ and $P=0.1786$, respectively).

\section{Histology}

At the end of the experiments, the animals were deeply anesthetized and recording sites marked with small electrolytic lesions (20 $\mu \mathrm{A}$ between a tetrode channel and the animal's tail for 15 $\mathrm{sec})$. One day later, the rats were then perfused-fixed through the heart, their brains extracted, cut on a vibrating microtome, and the sections counterstained with cresyl violet. An example of histologically identified recording site is shown in Figure 1B.

\section{Acknowledgments}

This work was supported by R01 grant MH-098738 from NIMH.

\section{References}

Alheid GF, Heimer L. 1988. New perspectives in basal forebrain organization of special relevance for neuropsychiatric disorders: The striatopallidal, amygdaloid, and corticopetal components of substantia innominata. Neuroscience 27: 1-39.

Amano T, Duvarci S, Popa D, Pare D. 2011. The fear circuit revisited: Role of the basal amygdala nuclei in conditioned fear. J Neurosci 31: 15481-15489.

Barthó P, Hirase H, Monconduit L, Zugaro M, Harris KD, Buzsáki G. 2004. Characterization of neocortical principal cells and interneurons by network interactions and extracellular features. J Neurophysiol 92: $600-608$.

Campeau S, Davis M. 1995. Involvement of subcortical and cortical afferents to the lateral nucleus of the amygdala in fear conditioning measured with fear-potentiated startle in rats trained concurrently with auditory and visual conditioned stimuli. J Neurosci 15: 2312-2327.

Campeau S, Falls WA, Cullinan WE, Helmreich DL, Davis M, Watson SJ. 1997. Elicitation and reduction of fear: Behavioural and neuroendocrine indices and brain induction of the immediate-early gene c-fos. Neuroscience 78: 1087-1104.

Ciocchi S, Herry C, Grenier F, Wolff SB, Letzkus JJ, Vlachos I, Ehrlich I, Sprengel R, Deisseroth K, Stadler MB, et al. 2010. Encoding of conditioned fear in central amygdala circuits. Nature 468: $277-282$.

Day HE, Curran EJ, Watson SJ, Akil H. 1999. Distinct neurochemical populations in the rat central nucleus of the amygdala and bed nucleus of the stria terminalis: Evidence for their selective activation by interleukin-1 $\beta$. J Comp Neurol 413: 113-128.

de Olmos JS, Heimer L. 1999. The concepts of the ventral striatopallidal system and extended amygdala. Ann $N$ Y Acad Sci 877: 1-32.

Dobolyi A, Irwin S, Makara G, Usdin TB, Palkovits M. 2005. Calcitonin gene related peptide containing pathways in the rat forebrain. J Comp Neurol 489: $92-119$

Dong HW, Swanson LW. 2003. Projections from the rhomboid nucleus of the bed nucleus of the stria terminalis: Implications for cerebral hemisphere regulation of ingestive behaviors. J Comp Neurol 463: $795-799$.

Dong HW, Swanson LW. 2004. Organization of axonal projections from the anterolateral area of the bed nuclei of the stria terminalis. J Comp Neurol 468: $277-298$.

Dong HW, Swanson LW. 2006a. Projections from bed nuclei of the stria terminalis, anteromedial area: Cerebral hemisphere integration of neuroendocrine, autonomic, and behavioral aspects of energy balance. J Comp Neurol 494: 142-178.

Dong HW, Swanson LW. 2006b. Projections from bed nuclei of the stria terminalis, magnocellular nucleus: Implications for cerebral hemisphere regulation of micturition, defecation, and penile erection. J Comp Neurol 494: 108-141.

Dong HW, Swanson LW. 2006c. Projections from bed nuclei of the stria terminalis, dorsomedial nucleus: Implications for cerebral hemisphere integration of neuroendocrine, autonomic, and drinking responses. J Comp Neurol 494: 75-107.

Dong HW, Petrovich GD, Swanson LW. 2000. Organization of projections from the juxtacapsular nucleus of the BST: A PHAL study in the rat. Brain Res 859: 1-14.

Dong HW, Petrovich GD, Swanson LW. 2001a. Topography of projections from amygdala to bed nuclei of the stria terminalis. Brain Res Brain Res Rev 38: 192-246.

Dong HW, Petrovich GD, Watts AG, Swanson LW. 2001b. Basic organization of projections from the oval and fusiform nuclei of the bed nuclei of the stria terminalis in adult rat brain. J Comp Neurol 436: $430-455$. 
Duvarci S, Bauer EP, Pare D. 2009. The bed nucleus of the stria terminalis mediates inter-individual variations in anxiety and fear. J Neurosci 29: 10357-10361.

Duvarci S, Popa D, Pare D. 2011. Central amygdala activity during fear conditioning. J Neurosci 31: 289-294.

Esclapez M, Tillakaratne N, Tobin AJ, Houser CR. 1993. Comparative localization of two forms of glutamic acid decarboxylase with nonradioactive in situ hybridization methods. J Comp Neurol 331: $339-362$.

Fendt M, Endres T, Apfelbach R. 2003. Temporary inactivation of the bed nucleus of the stria terminalis but not of the amygdala blocks freezing induced by trimethylthiazoline, a component of fox feces. J Neurosci 23: $23-28$.

Gewirtz JC, McNish KA, Davis M. 1998. Lesions of the bed nucleus of the stria terminalis block sensitization of the acoustic startle reflex produced by repeated stress, but not fear-potentiated startle. Prog Neuropsychopharmacol Biol Psychiatry 22: $625-648$.

Gungor NZ, Pare D. 2012. In vitro study of CGRP effects suggests that BNST-AL neurons exert an anxiolytic influence. In 2012 Neuroscience meeting planner, abstract program number 603.16. Society for Neuroscience, San Diego, CA.

Gustafson EL, Greengard P. 1990. Localization of DARPP-32 immunoreactive neurons in the bed nucleus of stria terminalis and central nucleus of amygdala: Co distribution with axons containing tyrosine hydroxylase, vasoactive intestinal polypeptide, and calcitonin gene related peptide. Exp Brain Res 1990: 447-458.

Hammack SE, Mania I, Rainnie DG. 2007. Differential expression of intrinsic membrane currents in defined cell types of the anterolateral bed nucleus of the stria terminalis. J Neurophysiol 98: $638-656$.

Hazan L, Zugaro M, Buzsaki G. 2006. Klusters, NeuroScope, NDManager: A free software suite for neurophysiological data processing and visualization. J Neurosci Methods 155: 207-216.

Hazra R, Guo J-D, Ryan SJ, Jasnow AM, Dabrowska J, Rainnie DG. 2011. A transcriptomic analysis of type I-III neurons in the bed nucleus of the stria terminalis. Mol Cell Neurosci 46: 699-709.

Herman JP, Mueller NK, Figueiredo H. 2004. Role of GABA and glutamate circuitry in hypothalamo-pituitary-adrenocortical stress integration. Ann N Y Acad Sci 1018: 35-45.

Hitchcock JM, Davis M. 1987. Fear-potentiated startle using an auditory conditioned stimulus: Effect of lesions of the amygdala. Physiol Behav 39: $403-408$.

Hitchcock JM, Davis M. 1991. Efferent pathway of the amygdala involved in conditioned fear as measured with the fear-potentiated startle paradigm. Behav Neurosci 105: 826-842.

Holstege G, Meiners L, Tan K. 1985. Projections of the bed nucleus of the stria terminalis to the mesencephalon, pons, and medulla oblongata in the cat. Exp Brain Res 58: 379-391.

Hopkins DA, Holstege G. 1978. Amygdaloid projections to the mesencephalon, pons and medulla oblongata in the cat. Exp Brain Res 32: $529-547$

Jennings JH, Sparta DR, Stamatakis AM, Ung RL, Pleil KE, Kash TL, Stuber GD. 2013. Distinct extended amygdala circuits for divergent motivational states. Nature 496: 224-228.

Jimenez SA, Maren S. 2009. Nuclear disconnection within the amygdala reveals a direct pathway to fear. Learn Mem 16: 766-768.

Ju G, Swanson LW. 1989. Studies on the cellular architecture of the bed nuclei of the stria terminalis in the rat: I. Cytoarchitecture. J Comp Neurol 280: 587-602.

Ju G, Swanson LW, Simerly RB. 1989. Studies on the cellular architecture of the bed nuclei of the stria terminalis in the rat: II. Chemoarchitecture. J Comp Neurol 280: 603-621.

Kim M, Campeau S, Falls WA, Davis M. 1993. Infusion of the non-NMDA receptor antagonist $\mathrm{CNQX}$ into the amygdala blocks the expression of fear-potentiated startle. Behav Neural Biol 59: 5-8.

Kim S-Y, Adhikary A, Lee SY, Marshel JH, Kim CK, Mallory CS, Lo M, Pak S, Mattis J, Lim BK, et al. 2013. Assembling behavioral states: Divergent neural pathways recruit separable anxiety features. Nature 496: 219-223.

Koo JM, Han JS, Kim JJ. 2004. Selective neurotoxic lesions of basolateral and central nuclei of the amygdala produce differential effects on fear conditioning. J Neurosci 24: 7654-7662.

Krettek JE, Price JL. 1978a. A description of the amygdaloid complex in the rat and cat with observations on intra-amygdaloid axonal connections. J Comp Neurol 178: 255-280.

Krettek JE, Price JL. 1978b. Amygdaloid projections to subcortical structures within the basal forebrain and brainstem in the rat and cat J Comp Neurol 178: 225-254.

Kudo T, Uchigashima M, Miyazaki T, Konno K, Yamasaki M, Yanagawa Y, Minami M, Watanabe M. 2012. Three types of neurochemical projection from the bed nucleus of the stria terminalis to the ventral tegmental area in adult mice. J Neurosci 32: $18035-18046$.

LeDoux JE, Iwata J, Cicchetti P, Reis DJ. 1988. Different projections of the central amygdaloid nucleus mediate autonomic and behavioral correlates of conditioned fear. J Neurosci 8: 2517-2529.

Markram H, Toledo-Rodriguez M, Wang Y, Gupta A, Silberberg G, Wu C. 2004. Interneurons of the neocortical inhibitory system. Nat Rev Neurosci 5: 793-807.

McDonald AJ. 2003. Is there an amygdala and how far does it extend? An anatomical perspective. Ann NY Acad Sci 985: 1-21.

McDonald AJ, Shammah-Lagnado SJ, Shi C, Davis M. 1999. Cortical afferents to the central extended amygdala. Ann N Y Acad Sci 877: 309-338.

Meloni EG, Jackson A, Gerety LP, Cohen BM, Carlezon WA Jr. 2006. Role of the bed nucleus of the stria terminalis (BST) in the expression of conditioned fear. Ann N Y Acad Sci 1071: 538-541.

Paré D, Smith Y, Paré JF. 1995. Intra-amygdaloid projections of the basolateral and basomedial nuclei in the cat: Phaseolus vulgaris-leucoagglutinin anterograde tracing at the light and electron microscopic level. Neuroscience 69: 567-583.

Pitts MW, Todorovic C, Blank T, Takahashi LK. 2009. The central nucleus of the amygdala and corticotropin-releasing factor: Insights into contextual fear memory. J Neurosci 29: 7379-7388.

Poulin JF, Arbour D, Laforest S, Drolet G. 2009. Neuroanatomical characterization of endogenous opioids in the bed nucleus of the stria terminalis. Prog Neuropsychopharmacol Biol Psychiatry 33: $1356-1365$.

Rodríguez-Sierra OE, Turesson HK, Pare D. 2013. Contrasting distribution of physiological cell types in different regions of the bed nucleus of the stria terminalis. J Neurophysiol (in press).

Savander V, Go CG, LeDoux JE, Pitkänen A. 1995. Intrinsic connections of the rat amygdaloid complex: Projections originating in the basal nucleus. J Comp Neurol 361: 345-368.

Sierra-Mercado D, Padilla-Coreano N, Quirk GJ. 2011. Dissociable roles of prelimbic and infralimbic cortices, ventral hippocampus, and basolateral amygdala in the expression and extinction of conditioned fear. Neuropsychopharmacology 36: 529-538.

Sink KS, Walker DL, Yang Y, Davis M. 2011. Calcitonin gene-related peptide in the bed nucleus of the stria terminalis produces an anxiety-like pattern of behavior and increases neural activation in anxiety-related structures. J Neurosci 31: 1802-1810.

Sofroniew MV. 1983. Direct reciprocal connections between the bed nucleus of the stria terminalis and dorsomedial medulla oblongata: Evidence from immunohistochemical detection of tracer proteins. J Comp Neurol 213: 388-405.

Sullivan GM, Apergis J, Bush DE, Johnson LR, Hou M, LeDoux JE. 2004. Lesions in the bed nucleus of the stria terminalis disrupt corticosterone and freezing responses elicited by a contextual but not by a specific cue-conditioned fear stimulus. Neuroscience 128: $7-14$.

Tepper JM, Bolam JP. 2004. Functional diversity and specificity of neostriatal interneurons. Curr Opin Neurobiol 14: 685-692.

Turesson HK, Rodriguez-Sierra O, Pare D. 2013. Intrinsic connections in the anterior part of the bed nucleus of the stria terminalis. J Neurophysiol 109: $2438-2450$

Veening JG, Swanson LW, Sawchenko PE. 1984. The organization of projections from the central nucleus of the amygdala to brainstem sites involved in central autonomic regulation: A combined retrograde transport-immunohistochemical study. Brain Res 303: 337-357.

Waddell J, Morris RW, Bouton ME. 2006. Effects of bed nucleus of the stria terminalis lesions on conditioned anxiety: Aversive conditioning with long-duration conditional stimuli and reinstatement of extinguished fear. Behav Neurosci 120: 324-326.

Walker DL, Davis M. 1997. Double dissociation between the involvement of the bed nucleus of the stria terminalis and the central nucleus of the amygdala in startle increases produced by conditioned versus unconditioned fear. J Neurosci 17: 9375-9383.

Walker DL, Miles LA, Davis M. 2009. Selective participation of the bed nucleus of the stria terminalis and CRF in sustained anxiety-like versus phasic fear-like responses. Prog Neuropsychopharmacol Biol Psychiatry 33: $1291-1308$.

Wilensky AE, Schafe GE, Kristensen MP, LeDoux JE. 2006. Rethinking the fear circuit: The central nucleus of the amygdala is required for the acquisition, consolidation, and expression of Pavlovian fear conditioning. J Neurosci 26: 12387-12396.

Yamaguchi T, Danjo T, Pastan I, Hikida T, Nakanishi S. 2013. Distinct roles of segregated transmission of the septo-habenular pathway in anxiety and fear. Neuron 78: 537-544.

Received May 12, 2013; accepted in revised form July 30, 2013. 


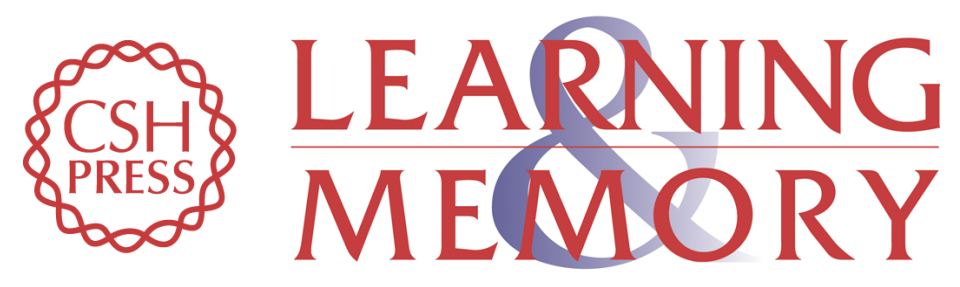

\section{Neuronal correlates of fear conditioning in the bed nucleus of the stria terminalis}

Darrell Haufler, Frank Z. Nagy and Denis Pare

Learn. Mem. 2013, 20:

Access the most recent version at doi:10.1101/Im.031799.113

References This article cites 62 articles, 13 of which can be accessed free at:

http://learnmem.cshlp.org/content/20/11/633.full.html\#ref-list-1

Creative This article is distributed exclusively by Cold Spring Harbor Laboratory Press for the

Commons first 12 months after the full-issue publication date (see

License

http://learnmem.cshlp.org/site/misc/terms.xhtml). After 12 months, it is available under a Creative Commons License (Attribution-NonCommercial 3.0 Unported), as described at http://creativecommons.org/licenses/by-nc/3.0/.

Email Alerting
Service Receive free email alerts when new articles cite this article - sign up in the box at the top right corner of the article or click here. 